\title{
Wind turbine doubly-fed asynchronous machine diagnosis defects using stator and rotor currents lissajous curves
}

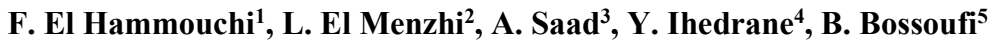 \\ ${ }_{1,3}$ National Higher School of Electricity and Mechanic, Hassan 2 University, Morocco \\ ${ }^{2}$ National School of Applied Sciences, AbdelmalekEssaadi University, Morocco \\ ${ }^{4}$ LISTA Laboratory, Faculty of Sciences Dhar El Mahraz, Sidi Mohammed Ben Abdellah University, Morocco \\ ${ }^{5}$ Laboratory of Electrical Engineering and Maintenance, Mohammed I University, Morocco
}

\begin{tabular}{l} 
Article Info \\
\hline Article history: \\
Received Oct 10, 2018 \\
Revised Nov 19, 2018 \\
Accepted Jan 30, 2019 \\
\hline Keywords: \\
Asynchronous generator \\
Diagnosis defect \\
Indirect field oriented control \\
Lissajous curves \\
Wind turbine
\end{tabular}

Corresponding Author:

Fatima El Hammouchi, Department of Electrical System, Hassan 2 University, National Higher School of Electricity and Mechanic, Casablanca 8118, Morocco.

Email: elhammouchi.fatima@gmail.com

\begin{abstract}
In the current paper, a method is developed to diagnose potential electrical defects attacking doubly fed induction generator in Moroccan wind turbines firms. The proposed method is based on stator and rotor currents Lissajous curves analysis. Firstly, we focus on modeling of a non-defected wind conversion systems based on mathematic model created in Matlab Simulink which is able to reflect the behaviour of the wind turbine during asynchronous generator defects-free operation. After that, an indirect stator field vector oriented control is applied to obtain the wind system performance. Finally, stator and rotor currents Lissajous curves are analyzed in case of a non-defected generator that represents the system reference curves for diagnosing defects. The simulations had been realized by Matlab Simulink. Their results showed the effectiveness of the proposed method.
\end{abstract}

Copyright (C) 2019 Institute of Advanced Engineering and Science. All rights reserved.

\section{INTRODUCTION}

It was extremely pressing, both for environmental and economic aspects, to look for alternative and clean energies in order to satisfy growing electricity needs, and reduce the $\mathrm{CO} 2$ emission [1]. For these reasons, many countries start exploring their natural and sustainable resources such as wind. Actually, considerable wind potential is located in lot of parts of the world. This potential is completely free, inexhaustible and renewable. However, the wind energy cost remains high due to the expensive operational and maintenance costs $(\mathrm{O} \& \mathrm{M})$ of wind turbines. Indeed, these big structures are usually situated in remote locations that are hard to access. So, the maintenance costs can reach from $10 \%$ to $30 \%$ of the wind turbines total income [2]. These costs could be reduced by monitoring continuously the system health [3], especially the generator. This crucial part of wind turbine is responsible of electricity production and its transmission to the grid.

In fact, the Doubly Fed Induction Generator (DFIG) is the most used in the wind turbine variable speed industry [4]. It offers excellent operational and control features that make their integration with power grids easy and effective [5]. Much research deals with different methods to improve the electrical energy performance and production from wind [6]. Most of it develops control lows for DFIG to extract maximum electrical power from wind turbine $[7,8]$. But, during their operation, the DFIG can be exposed to difficult conditions or manufacturing defects $[9,10]$, which can immediately paralyze electricity production and lead to a loss of structure [11]. Thus, the defects must be predicted on time. 
A lot of works have been done to inspect DFIG faults. Some research is using available techniques like Supervisory Control And Data Acquisition SCADA [12]. Others use data derived from condition and Structural Health Monitoring (SHM) to detect wind turbine faults by using decision tree learning algorithms with big data [13].

Hence, the generator diagnosis defects provides early detection of imminent faults, and minimizes wind turbine downtime [14]. Also, it anticipates serious damage affecting wind energy system by predicting any defects, stopping their propagation and saving time and money. In order to detect defects and their causes, the diagnostic system has to use data from normal operation and compare it with defects characteristics. So, a new method is proposed for having reliable reference system in case of non-defected DFIG so as to predict the prospective defects.

In the first part of this research, a description of the essential wind energy conversion systems components is presented. In the second part, wind turbine behavior during defects-free operation of DFIG is treated using mathematical equations to create model in Matlab Simulink. In the last part, stator and rotor currents Lissajous curves are developed as a method for DFIG diagnosis defects. The simulation results, obtained by Matlab Simulink, show the efficiency of the proposed approach.

\section{WIND CONVERSION SYSTEM MODELING}

The study will be about two Moroccan wind turbine firms that contain horizontal-axis HAWT using DFIG. In fact, the DFIG is an asynchronous machine fed from the stator and rotor. The rotor of DFIG is connected to the grid through the transformer and the voltage source converters "back-to-back": the Rotor Side Converter (RSC) and the Grid Side Converter (GSC). A capacitor is placed between two converters to reduce the voltage ripples. The RSC controls features of the active and reactive powers, the developed torque and the rotation speed. So, the GSC controls the DC bus voltage and the grid factor.

\subsection{Wind turbine modeling}

The wind speed used in the model is a sum of sinusoidal signals with different frequencies and amplitudes as shown in the Figure 1 below.

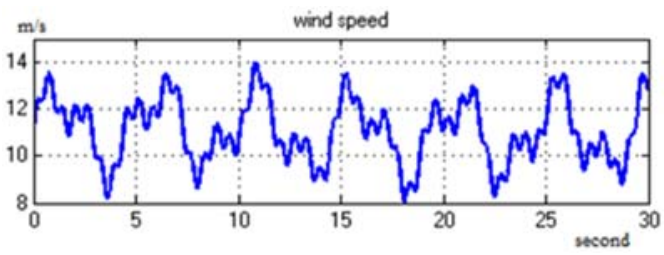

Figure 1. Wind speed model

By applying the theory of momentum and Bernoulli's theorem, incident theoretical power due to wind $P_{\text {wind }}$ is expressed by the equation below:

$$
P_{\text {wind }}=\frac{\delta}{2} \cdot A \cdot v^{3}
$$

$P_{\text {wind }}$ : Wind power; $\delta$ : Air Density; A: Sweep area swept by the blade; $v:$ Wind speed. The Power captured by the blade $P_{\text {turb }}$ is determined by the equation below:

$$
P_{\text {turb }}=\frac{\delta}{2} \cdot A \cdot C_{p}(\lambda, \beta) \cdot v^{3}
$$

With

$$
\boldsymbol{C}_{\boldsymbol{p}}(\lambda, \beta)=\boldsymbol{k}_{1} \cdot\left(\boldsymbol{k}_{2} \cdot \boldsymbol{K}-\boldsymbol{k}_{3} \cdot \beta-\boldsymbol{k}_{4}\right) \cdot e^{-\boldsymbol{k}_{5} K}+\boldsymbol{k}_{6} \cdot \lambda
$$




$$
\begin{aligned}
& \boldsymbol{K}=\frac{1}{\lambda+\boldsymbol{k}_{7} \cdot \beta}-\frac{\boldsymbol{k}_{8}}{1+\beta^{3}} \\
& \lambda=\frac{\boldsymbol{W}_{\text {turb }} \cdot \boldsymbol{R}}{\boldsymbol{v}}
\end{aligned}
$$

$C_{p}(\lambda, \beta):$ Coefficient of performance

$\lambda$ : Tip-speed ratio

$\beta$ : Pitch angle ( $\beta=0$ for maximum $\boldsymbol{C}_{\boldsymbol{p}}$ )

$\mathrm{W}_{\text {turb }}$ : Angular speed of the blade

In order to have $\beta=0$ for a maximum $C_{\boldsymbol{p}}: \mathrm{k} 1=0.5872, \mathrm{k} 2=116, \mathrm{k} 3=0.4, \mathrm{k} 4=5, \mathrm{k} 5=21, \mathrm{k} 6=0.0085$, $\mathrm{k} 7=0.08, \mathrm{k} 8=0.035$ [15]. The aerodynamic torque on the main shaft (slow axis) $T_{\text {turb }}$ can be expressed by the equation:

$$
\begin{aligned}
& T_{\text {turb }}=\frac{P_{\text {turb }}}{W_{\text {turb }}}=\frac{\delta}{2} \cdot A \cdot C_{p}(\lambda, \beta) \cdot v^{3} \cdot \frac{1}{W_{\text {turb }}} \\
& \boldsymbol{J}=\frac{\boldsymbol{J}_{\text {turb }}}{\boldsymbol{G}^{2}}+\boldsymbol{J}_{\boldsymbol{g}}
\end{aligned}
$$

$\mathrm{T}_{\text {turb: }}$ Blade torque

$\mathrm{J}$ : Inertia of the system brought back on the turbine fast axis

$\mathrm{J}_{\text {turb }}$ : Turbine inertia

G: Gearbox ratio

Jg: Generator inertia

The fundamental equation of dynamics is applied to determine the evolution of the DFIG mechanical speed which is presented in equation below:

$$
J \frac{d W_{m e c}}{d t}=T_{g}-T_{e m}-f . W_{m e c}
$$

$\mathrm{W}_{\text {mec }}$ : DFIG mechanical speed

$\mathrm{T}_{\mathrm{g}}$ : Aerodynamic torque on the the turbine fast axis

$\mathrm{T}_{\mathrm{em}}$ : Electromagnetic torque

$\mathrm{f}$ : Friction coefficient

The equations presented above, are used to create the wind turbine Matlab-Simulink. We suppose that the frictions are neglected. The system performance is showed in Figures 3, 4, 5 and 6.

\subsection{Mdeling of doubly-fed induction machine}

The asynchronous machine equations for the stator Us and the rotor Ur voltages in Park reference frame $(\mathrm{d}, \mathrm{q})$ are $[16]$ :

$$
\left\{\begin{array}{l}
U_{d s}=\frac{d \phi_{d s}}{d t}+R_{s} . i_{d s}-\phi_{q s} \omega_{s} \\
U_{q s}=\frac{d \phi_{q s}}{d t}+R_{s} . i_{q s}+\phi_{d s} \omega_{s} \\
U_{d r}=\frac{d \phi_{d r}}{d t}+R_{r} \cdot i_{d r}-\phi_{q r}\left(\omega_{s}-\omega_{r}\right) \\
U_{q r}=\frac{d \phi_{q r}}{d t}+R_{r} \cdot i_{q r}+\phi_{d r}\left(\omega_{s}-\omega_{r}\right)
\end{array}\right.
$$

With: $\omega_{r}=\omega_{s}-\boldsymbol{P} . \boldsymbol{w}$

$\boldsymbol{U}_{\boldsymbol{s}}(\mathrm{d}, \mathrm{q}), \boldsymbol{U r}(\mathrm{d}, \mathrm{q})$ : Stator and rotor voltage Park components respectively;

$\phi_{s}(\mathrm{~d}, \mathrm{q}), \phi_{r}(\mathrm{~d}, \mathrm{q})$ : Stator and rotor flux Park components respectively;

Wind turbine doubly-fed asynchronous machine diagnosis defects using stator ... (F. El Hammouchi) 
$i_{s}(\mathrm{~d}, \mathrm{q}), \boldsymbol{i}_{\boldsymbol{r}}(\mathrm{d}, \mathrm{q})$ : Stator and rotor currents in Park components respectively;

$\mathrm{Rs}, \mathrm{Rr}$ : Stator and rotor resistances respectively. The flux equations can be written as follows:

$$
\begin{aligned}
& \left\{\begin{array}{l}
\phi_{d s}=L_{s} \cdot i_{d s}+M \cdot i_{d r} \\
\phi_{q s}=L_{s} \cdot i_{q s}+M . i_{q r} \\
\phi_{d r}=L_{r} \cdot i_{d r}+M \cdot i_{d s} \\
\phi_{q r}=L_{r} \cdot i_{q r}+M . i_{q s}
\end{array}\right. \\
& L_{s}=I_{s}-M{ }_{s}, \quad L_{r}=I_{r}-M_{r}
\end{aligned}
$$

Ls, Lr : Stator and rotor cyclic inductances respectively;

1s, lr : Stator and rotor leakage inductances respectively;

Ms, Mr : Mutual inductances between stator phases and rotor phases respectively;

M : Maximum mutual inductance between stator and rotor stages;

$\boldsymbol{p}$ represents the DFIG pole pairs number. The electromagnetic torque expression is:

$$
T_{e m}=p\left(\phi_{d s} \cdot i_{q s}-\phi_{q s} \cdot i_{d s}\right)
$$

\subsection{Field oriented control}

The purpose of orienting the stator field is to perform the DFIG active and reactive powers by controlling dynamically and separately the flux and the torque. That means orienting stator flux along the direct axis in order to obtain: $\phi_{\boldsymbol{q} \boldsymbol{s}}=0$ and $\phi_{\boldsymbol{s}}=\phi_{\boldsymbol{s} \boldsymbol{d}}$. From (11) and (12) we get:

$$
\left\{\begin{array}{l}
i_{d s}=\frac{1}{L s}\left(\phi_{s}-M . i_{d r}\right) \\
i_{q s}=-\frac{M}{L s} . i_{q r} \\
T_{e m}=p \phi_{s} . i_{q s}=-p \frac{M}{L s} \phi_{s} . i_{q r}
\end{array}\right.
$$

In general, the stator resistance is neglected for large power equipment used in wind turbine. It is supposed that the grid is stable and the field is constant. The stator voltage park components (9) become:

$$
\left\{\begin{array}{l}
U_{d s}=0 \\
U_{q s}=\phi_{s} \omega_{s}
\end{array}\right.
$$

The DFIG active and reactive powers can be written as follows:

$$
\left\{\begin{array}{l}
P_{s}=U_{d s} . i_{d s}+U_{q s} . i_{q s} \\
Q_{s}=U_{q s} \cdot i_{d s}-U_{d s} \cdot i_{q s}
\end{array}\right.
$$

By using (14), the active and reactive powers expressions become:

$$
\left\{\begin{array}{l}
P_{s}=-U_{s} \frac{M}{L s}, i_{q r} \\
Q_{s}=\frac{U^{2}{ }_{s}}{\omega_{s} \cdot L_{s}}-U_{s} \frac{M}{L s}, i_{d r}
\end{array}\right.
$$

So the active power is independent of the reactive power. It is controlled by the quadrature rotor current iqr. The reactive power is controlled by direct rotor current idr. 


$$
\left\{\begin{array}{l}
U_{d r}=\left(R_{r}+S\left(L_{r}-\frac{M^{2}}{L s}\right)\right) \cdot i_{d r}-g \omega_{s}\left(L_{r}-\frac{M^{2}}{L s}\right) \cdot i_{q r} \\
U_{q r}=\left(R_{r}+S\left(L_{r}-\frac{M^{2}}{L s}\right)\right) \cdot i_{q r}+g \omega_{s}\left(L_{r}-\frac{M^{2}}{L s}\right) \cdot i_{q r}+g \frac{M}{L s} \cdot U_{s}
\end{array}\right.
$$

There are two approaches of the vector control: direct and indirect. The direct one is simple to implement [17] but not the most efficient [18, 19] because it ignores the terms of coupling. The indirect method is being more commonly used [20] because it allows operating more easily throughout all the speed range [21].

In order to have performing system, the wind turbine model is implemented in Matlab Simulink by using the indirect method (IFOC). The orientation of the DFIG stator flux is chosen according to the direct axis. The overall pattern of the wind system model is presented in Figures 7, 8, 9 and 10.

\section{DIAGNOSIS OF NON DEFECTED WIND CONVERSION SYSTEM}

Unfortunately, wind turbine faults occur once it starts working. Indeed, Wind energy has its congenital defects due for example to the harsh operating environment and the highly turbulent wind speed [22]. But, under whatever operation conditions, the stability and reliability of wind turbine are requisited to the grid. Hence, the diagnosis of wind turbine should be realized. In this part, we diagnose a non-defected system to have a reliable reference.

\subsection{Review of diagnosis defects essential methods}

For minimizing downtime, predicting in time imminent failures and improving maintenance schedule, several techniques are applied for monitoring continuously the wind energy conversion system health [23]. Indeed, online diagnosis defects allows an early detection of the structure health degradation and prevents incipient faults in the wind energy conversion system which leads to save both money and time. Multitude of internal and external defects attacks frequently wind turbines once its start working [24] especially the generator. Indeed, DFIG undergoes some common defects such as generator excessive vibration, generator overheating, bearing overheating, abnormal noises and insulation damage, etc [25].

Much research on generator faults deals with methods of process simulation and algorithm construction which are used in condition monitoring to detect and anticipate defects [26]. Other techniques use time-frequency analysis tools, such as wavelets, to derive a fault detection signal [27]. Some methods are also exploring data provided by the supervisory system and applying many data-mining algorithms to develop models for predicting occurrence of possible defects [28]. These different techniques are widely used in control system for reducing the wind turbine downtime and minimizing operational and maintenance costs.

\subsection{Method developed for DFIG diagnosis defects using Lissajous curves}

The Lissajous curves are studied first by the American mathematician Nathaniel Bowditch in 1815. The curves, in 1857-1858, were investigated independently by the French mathematician Jules-Antoine Lissajous. The French mathematician used a narrow stream of sand pouring from the base of a compound pendulum to produce the curves $[29,30]$.

Lissajou figures are created by the combination of two sine waves: the $\mathrm{x}$ signal is described by one sine wave, and the y signal is described by another sine wave. So by expressing $\mathrm{y}$ as a function of $\mathrm{x}$, interesting patterns are created. Recent developments in the field of Lissajous curves are realized in different domains such as the rotating machinery field [31], and faults diagnosis [32].

Lissajous curves are described by the parametric equations below [33]:

$$
x=A \sin (a t+\alpha) \quad y=B \sin (b t)
$$

If the two waves have exactly the same frequency $(\mathrm{a}=\mathrm{b})$, the same amplitude $(\mathrm{A}=\mathrm{B})$, with an angle $\alpha=\pi / 2$, the parametric as shown in 18 become:

$$
\begin{aligned}
& x=A \cos (\text { at) } \quad y=A \sin (a t) \\
& x^{2}+y^{2}=A^{2}
\end{aligned}
$$

Then the resultant output will be a circle. In this view, Lissajous curves are applied in this paper to the DFIG stator and rotor three-phase currents. For this purpose, it is necessary to use the Concordia transformation 
[34] in order to obtain the stator and rotor currents Concordia components (is $\alpha$, ir $\alpha$ ) and (is $\beta$, ir $\beta$ ) from the three-phase stator basic currents is $\mathrm{abc}_{\mathrm{a}}$ and the three-phase rotor basic such as:

$$
\left[\begin{array}{l}
i \alpha \\
i \beta
\end{array}\right]=\frac{\sqrt{2}}{3}\left[\begin{array}{ccc}
1 & -1 / 2 & -1 / 2 \\
0 & \frac{\sqrt{3}}{2} & -\frac{\sqrt{3}}{2}
\end{array}\right] *\left[\begin{array}{c}
i a \\
i b \\
i c
\end{array}\right]
$$

Matlab Simulink software is used for simulating a non-defected system. The results are presented in Figure 13 and Figure 14. These curves are considered as a reference to which the defected system curves will be compared in future works.

\section{RESULTS AND ANALYSIS}

The results below represent the simulation of the wind turbine model in Matlab Simulink at the first thirty seconds. The results are obtained by choosing the following values on Table 1 .

Table 1. Model parameters

\begin{tabular}{ccc}
\hline $\begin{array}{c}\text { Turbine } \\
\text { parameters }\end{array}$ & $\begin{array}{c}\text { Coefficients for } \\
\text { maximum } \mathrm{Cp}\end{array}$ & $\begin{array}{c}\text { Machine } \\
\text { Parameters }\end{array}$ \\
\hline$\delta=1.225 \mathrm{~kg} / \mathrm{m}^{3}$ & $\mathrm{k} 1=0.5872$ & $\mathrm{Rs}=0.012 \Omega$ \\
$\mathrm{A}=3903.625 \mathrm{~m}^{2}$ & $\mathrm{k} 2=116$ & $\mathrm{Rr}=0.021 \Omega$ \\
$\mathrm{R}=35.25 \mathrm{~m}$ & $\mathrm{k} 3=0.4$ & $\mathrm{Ls}=0.0137 \mathrm{H}$ \\
$\mathrm{G}=90 ;$ & $\mathrm{k} 4=5$ & $\mathrm{Lr}=0.0136 \mathrm{H}$ \\
$\mathrm{j}=1000 ;$ & $\mathrm{k} 5=21$ & $\mathrm{M}=0.0135 \mathrm{H}$ \\
$\mathrm{f}=0.0024 ;$ & $\mathrm{k} 6=0.0085$ & $\mathrm{~g}=0.003$ \\
$\beta=0^{\circ}$ & $\mathrm{k} 7=0.08$ & \\
& $\mathrm{k} 8=0.035$ & \\
\hline
\end{tabular}

The wind system is exposed to variable wind speed from $8(\mathrm{~m} / \mathrm{s})$ to $14(\mathrm{~m} / \mathrm{s})$ as shown in Figure 2 . From (1) we obtain Figure 3 which represents the wind power $P_{\text {wind. }}$ Then, by using (2) we get the power captured by the blade Pturb as shown in Figure 4. The Figures 5, 6 and 7 show the system performances. In deed, we can see that the tip speed ratio is almost constant as illustrated in Figure 5. The coefficient of performance reaches its maximum value which is 0.57 .

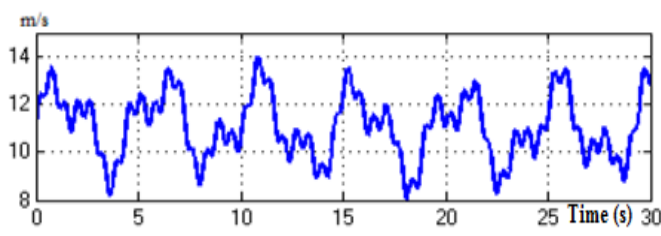

Figure 2. Wind speed $(\mathrm{m} / \mathrm{s})$

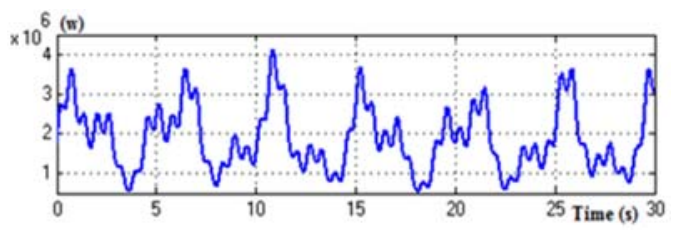

Figure 4. Pturb power captured by the blade

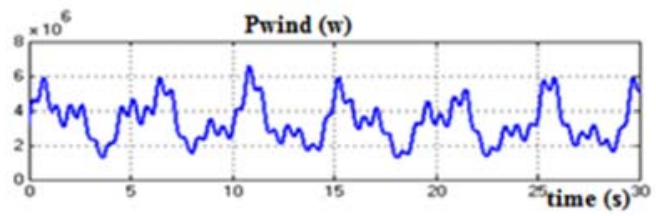

Figure 3. Pwind

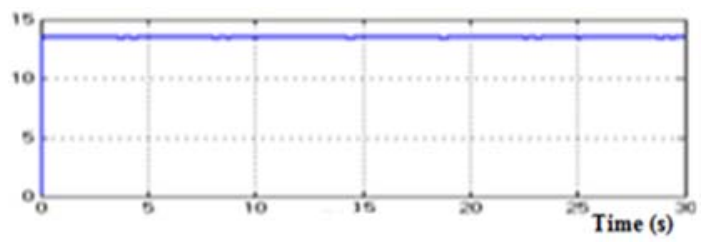

Figure 5. Tip-speed ratio 


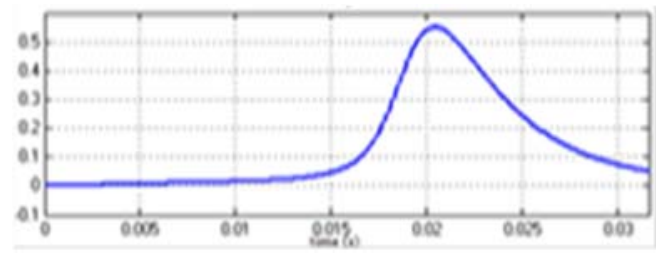

Figure 6. Coefficient of performance

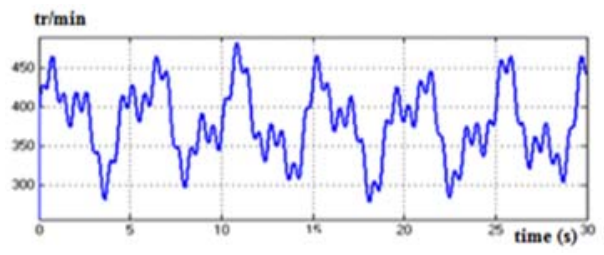

Figure 7. Mechanical speed of DFIG

The stator flux of DFIG is oriented according to the direct axis that is why the machine stator indirect flux, in Figure 8, reaches zero and the stator direct flux is constant as shown in Figure 9. In addition, the indirect field oriented control is used to control active and reactive powers. A reference for active power Psref is chosen to have a form of steps ( 3 steps). The Figure 10 shows a comparison between power reference and real active power. It is clear that the real active power follows the power reference. The system real reactive power is also around the reactive power reference which is zero Figure 11. Stator three phase currents are presented in Figure 12 from which shows that DFIG three-phase stator currents is abc have a perfect sinusoidal shape. By using (15), the stator currents are influenced by Psref. For this reason, three variation zones of stator currents are observed. These figures show that the wind system model implemented in the Matlab Simulink react rapidly and has a satisfactory dynamic.

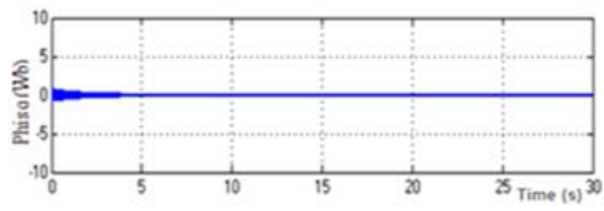

Figure 8. Indirect stator field of DFIG

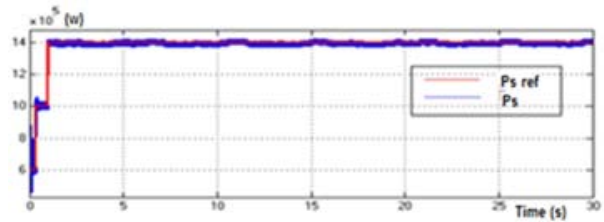

Figure 10.Comparison between Psref and Ps

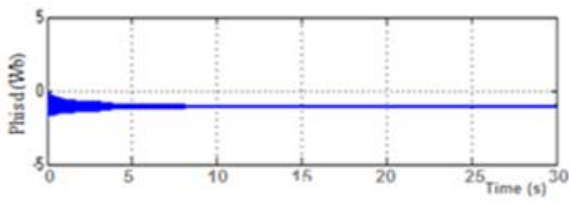

Figure 9. Direct stator field of DFIG

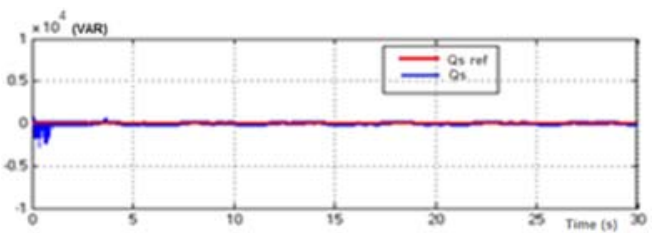

Figure 11. Comparison between Qsref and Qs

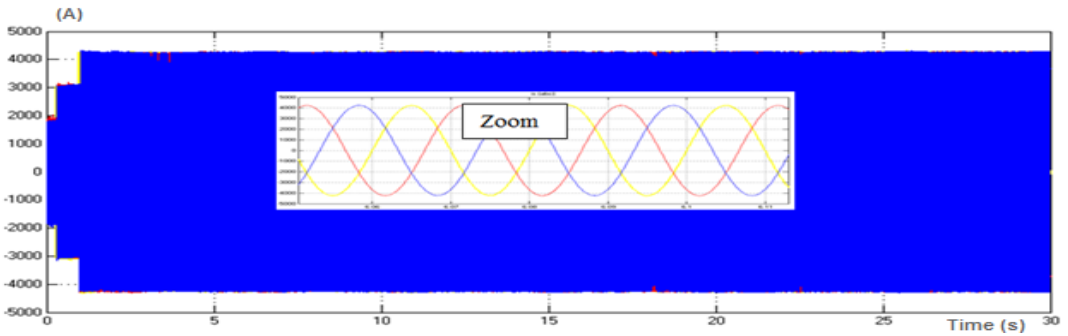

Figure 12. Stator currents phases $\mathrm{a}, \mathrm{b}$ and $\mathrm{c}$

The Figures 13 and 14 expose Lissajous curves of a DFIG sator and rotor currents during freedefects operation. Each curve, has three circular shapes passing from the small circle to the biggest one. Theses three circles are obtained because the Psref is chosen as a signal with three steps. In deed, at the simulation starting time and after application of the active power reference signal first step Psref, the first

Wind turbine doubly-fed asynchronous machine diagnosis defects using stator ... (F. El Hammouchi) 
circle is obtained. At 0.3 second, another step is added to the first step. Thus, the second circle is drown. Finally, at one second, we apply the third step that lead us to get the third circle.

The rotor currents Lissajous curves are showed in Figure 13. It has a 6 petals flower shape. This shape is due to the DFIG rotor supply by the inverter with 6 switches. The DFIG currents Lissajous curves will give an idea, in fure works, about the kind of the defects attacking wind conversion system. So, when the defects occur, the Lissajous curves will have other shapes.

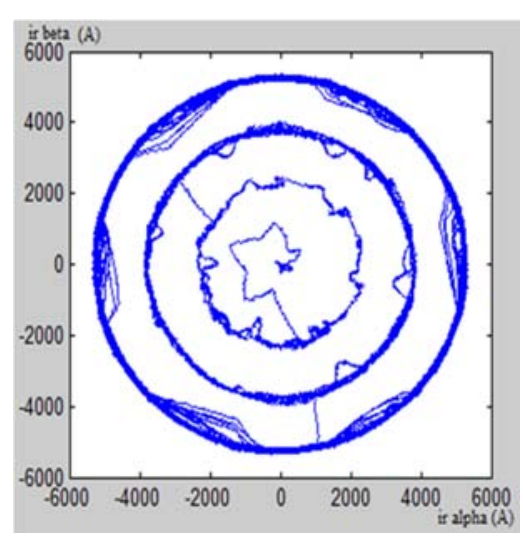

Figure 13. Rotor Lissajous curves

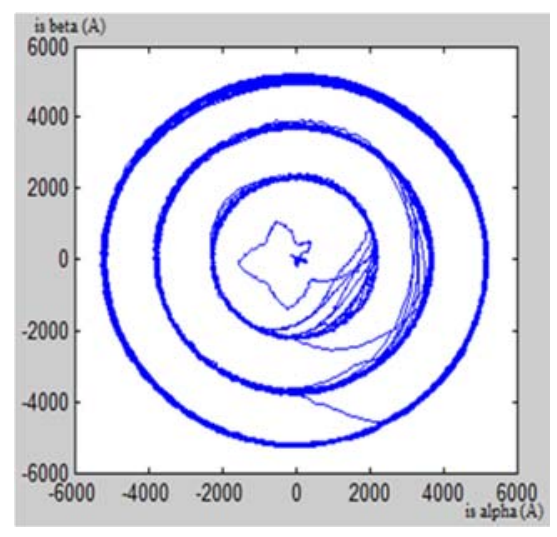

Figure 14. Stator Lissajous curves

\section{CONCLUSION}

In the first part of this paper, the wind conversion systems modelling based on mathematical equations is presented. Then, an indirect vector control stator field oriented is applied to increase the performance of the wind conversion chain. The system is simulated by Matlab Simulink during defects-free operation. In the second part, a method was developed to predict the potential electrical defects attacking wind turbine using Lissajous curves of the DFIG stator and rotor currents.

The obtained results are considered as a reliable reference system for DFIG diagnosis of Morocan wind turbines parks. To this reference system, the wind conversion energy behaviour will be compared in the case of the defects. The next work will be devoted to modelling and simulation of defected wind energy conversion system. Lissajous curves and frequency spectrum will be used in order to analyse and diagnose different defects attacking the two Moroccan wind turbines parks.

\section{REFERENCES}

[1] United Nations Climate Change Conference (COP22), in Marrakech, November 2016.

[2] Z. L. Yin, et al., "Startup Speed with Dead Band in Wind Farms with Low-Medium Wind Speed Profile-Case Study of Hong Kong", Energy and Power Engineering, vol. 9, pp. 562-572, April 2017.

[3] Y. Amirata, et al., "A Brief Status on Condition Monitoring and Fault Diagnosis in Wind Energy Conversion Systems", Renewable and Sustainable Energy Reviews, vol. 13, issue 9, pp. 2629-2636, 2009.

[4] R. M. R. Muthu, "Doubly Fed Induction Generator for Wind Energy Conversion System - a Survey", International Conference on Energy Efficient Technologies for Sustainability, pp. 617-628, 2013.

[5] M. A. El-Sharkawi, "Wind Energy An Introduction", University of Washington, Seattle, USA, pp. 219, 2016.

[6] K. Belgacem , A. Mezouar and N. Essounbouli, "Design and Analysis of Adaptive Sliding Mode with Exponential Reaching Law Control for Double-Fed Induction Generator Based Wind Turbine", International Journal of Power Electronics and Drive System (IJPEDS), vol. 9, no. 4, pp. 1534-1544, December 2018.

[7] D. C. Phan and T. H. Trinh, "Maximum Power Extraction Method for Doubly-fed Induction Generator Wind Turbine", International Journal of Electrical and Computer Engineering (IJECE), vol. 8, no. 2, pp. 711 - 722, April 2018.

[8] A. A. Bensaber, et al., "Nonlinear Adaptive Control for Wind Turbine under Wind Speed Variation", International Journal of Robotics and Automation (IJRA), vol. 7, no. 2, pp. 87-95, June 2018.

[9] S. Martens et al., "Simulation of Electric Faults in Doubly-Fed Induction Generators Employing Advanced Mathematical Modelling", Proceedings of 24th Nordic Insulation Symposium on Materials, Components and Diagnostic, pp.98-104, 2015.

[10] A.Joshuva and V.Sugumaran, "Fault Diagnostic Methods for Wind Turbine: A Review", Journal of Engineering and Applied Sciences (ARPN), vol. 11, no 7, pp. 4654-4668, 2016.

Int J Pow Elec \& Dri Syst, Vol. 10, No. 2, June 2019 : 961 - 970 
[11] F. El Hammouchi, L. El Menzhi and A. Saad, "Wind Turbine Doubly-Fed Asynchronous Machine Diagnosis Defects-State of the Art", DEStech Transactions on Environment Energy and Earth Sciences, pp. 300-306, October 2017.

[12] S. Sharma and D. Mahto, "Condition Monitoring of Wind Turbines: A Review", International Journal of Scientific \& Engineering Research, vol. 4, issue 8, pp. 35-49, 2013.

[13] Abdallah, et al., "Fault Diagnosis of Wind Turbine Structures Using Decision Tree Learning Algorithms with Big Data", Proceedings of Safety and Reliability Conference, pp. 3053-3061, no. 3, June 2018.

[14] N. Tazi, E. Chatelet, Y. Bouzidi, et al., "Wind Farm Topology-Finding Algorithm Considering Performance, Costs, and Environmental Impacts", Environmental Science and Pollution Research, vol. 25, issue 25, pp. 24526-24534, September 2018.

[15] B. Bossoufi, et al., "Observer Backstepping Control of DFIG-Generators for Wind Turbines Variable-Speed: FPGA-Based Implementation", Renewable Energy, vol. 81, pp. 903-917, 2015.

[16] B. Bossoufi , et al., "Backstepping Control of DFIG Generators for Wide-Range Variable-Speed Wind Turbines", International Journal of Automation and Control (IJAC), vol. 8, no. 2, pp.122-140, 2014.

[17] Y. Ihedrane, C. ElBekkali, and B. Bossoufi, "Power Control of DFIG-Generators for Wind Turbines VariableSpeed", International Journal of Power Electronics and Drive System (IJPEDS), vol. 8, no. 1, pp. 444-453, 2017.

[18] M. Allam, et al., "Etude Comparative Entre la Commande Vectorielle Directe et Indirecte de la Machine Asynchrone à Double Alimentation (MADA) Dédiée à une Application Eolienne", Journal of Advanced Research in Science and Technology (JARST), vol.1,issue 2, pp. 88-100, 2014.

[19] B. Bossoufi, M. Karim, A. Lagrioui and M. Taoussi, "FPGA-Based Implementation Nonlinear Backstepping Control of a PMSM Drive", International Journal of Power Electronics and Drive System (IJPEDS), vol. 4, issue1, pp. 12-23, 2014.

[20] K. Sejir, "CommandeVectorielle d'une Machine Asynchrone Doublement Alimentée (MADA)", Thèse de Doctorat, de l'Institut National Polytechnique de Toulouse, France, 2006.

[21] Gan Dong, "Sensorless and Efficiency Optimized Induction Machine Control with Associated Converter PWM Modulation Schemes", the Faculty of the Graduate School, Tennessee Technological University, 2005.

[22] K. Ma, et al., "Active Power Dispatch Strategy of Wind Farms under Generator Faults", Proceedings of the European Safety and Reliability Conference: Safe Societies in a Changing World, 1st ed., pp. 2147-2152 London, UK: CRC Press, 2018.

[23] F. El Hammouchi, L. El Menzhi, A. Saad, Y. Ihedrane, B. Bossoufi, "Wind Turbine Doubly-Fed Asynchronous Machine Diagnosis Defects-part two", Congress CIST 18 Conference OMCS, IEEE XPLORE, catalogue number CFP1867R-ART, pp. 486-454, 2018.

[24] F. El Hammouchi, L. El Menzhi, A. Saad, "Wind Turbine Double-fed Asynchronous Machine Diagnosis DefectsPart One", International Congress of Industrial Engineering and Systems Management CIGIMS, Meknes, Morocco, pp. 380-383, Mai 2017.

[25] A. Joshuva and V. Sugumaran, "Fault Diagnostic Methods For Wind Turbine: A Review", Journal of Engineering and Applied Sciences (ARPN), vol. 11, no. 7, pp. 4654-4668, 2016.

[26] S.M. Tabatabaeipour, et al., "Fault Detection of Wind Turbines with Uncertain Parameters: A Set-Membership Approach", Energies, vol. 5, issue 7, pp. 2224-2248, 2012.

[27] W.Yang, P.J. Tavner, C. J.Crabtree and M. Wilkinson. "Cost-Effective Condition Monitoring for Wind Turbines", IEEE Transactions on Industrial Electronics, vol. 57, no.1, pp. 263-271, 2010.

[28] A. Kusiak and W. Li, "The Prediction and Diagnosis of Wind Turbine Faults", Renewable Energy, vol. 36, issue 1, pp. 16-23, 2011.

[29] H. Cundy, and A. Rollett, "Lissajous's Figures in Mathematical Models", 3rd ed. Stradbroke, England: Tarquin Pub. 1989.

[30] A. Gray, "Modern Differential Geometry of Curves and Surfaces with Mathematica", 2nd ed. Boca Raton, FL: CRC Press, 1997.

[31] H. A. H. Al-Khazali and M. R. Askari, "Geometrical and Graphical Representations Analysis of Lissajous Figures in Rotor Dynamic System", Journal of Engineering (IOSR), vol. 2, issue 5, pp. 971-978, 2012.

[32] L. El Menzhi, and A. Saad, "Lissajous Curve of an Auxiliary Winding Voltage Park Components for Doubly-Fed Induction Machine Electrical Faults Diagnosis", The Journal of Advanced Materials Research, vol.860-863, pp. 2223-2231, 2014.

[33] H. G. Yiyang, "Demonstrating Lissajous Figures with Matlab and Their Applications", Journal of China Science and Technology Information, Electronic \& Industrial College, Yiyang Hunan 413054, 2, China, 2008.

[34] B. Bossoufi, M. Karim, S. Ioniłă and A. Lagrioui, "Performance Analysis of the Direct Torque Control and the Space Vector Modulation for Permanent Magnet Synchronous Motor Drive", University of Pitesti Scientific Bulletin : Electronics And Computers Science, vol.10, issue 2, pp 23-34, 2010. 


\section{BIOGRAPHIES OF AUTHORS}
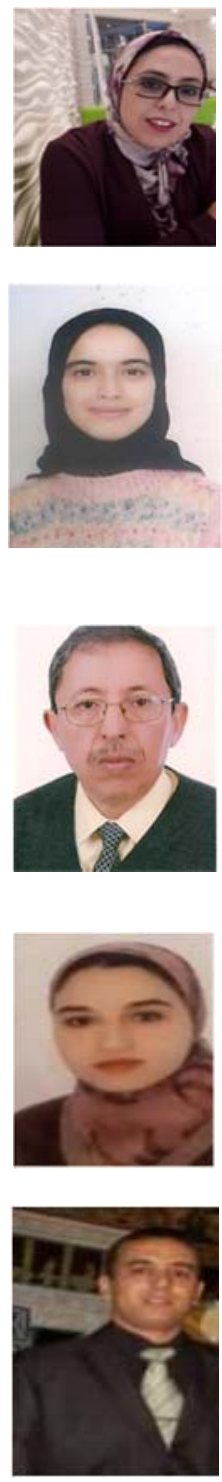

Fatima El Hammouchi was born in Morocco on October 16th, 1985. In 2008, She received the Engineer degree in Electrical Engineering and Power Electronics (EEP) from the National Higher School of Electricity and Mechanics (ENSEM) Hassan 2 University of Morocco in Casablanca. She is $\mathrm{PhD}$ student in electrical engineering at Electrical Systems Team (EST) of ENSEM since 2015.

She is interested in electrical machines modelling, control, online diagnosis defects in wind turbines, and their integration in grid.

Lamiaa El Menzhi is a professor in Abdelamalek Essaadi University in Morocco since 2010. On 2002, She got her High Deepened Studies Diploma in electrical machines in electrical engineering from the High National School of Electricity and Mechanics ENSEM in Hassan 2 University in Casablanca. From 2002 until 2004, she was a research student in one of the universities in japan. On 2009, she obtained her Doctor degree, then her Habilitation as a professor researcher on 2016 from Hassan 2 University in Casablanca (ESEM). She is interested in electrical machines control and on-line diagnosis either used as a motor or a generator in wind turbines. Lamiaa El Menzhi is a member and advisor of the Moroccan Center of Polytechnical Research and Innovation since 2015.

Abdallah Saad was born in Morocco in September 1956. He received the Engineer and Doctor of Engineering degrees from National Polytechnic Institute of Grenoble - France - respectively in 1980 and 1982. From 1982 to 1986, he was Researcher at French National Center for Scientific Research (CNRS) - Electrostatics and Dielectric Materials Laboratory - Grenoble. After receiving the Doctor of Physical Sciences degree in 1986, he joined Hassan 2 University of Morocco. Professor of electrical engineering, he has several scientific and educational responsibilities. His main fields of interest are High Voltage and Electrical Insulations, modeling and control, renewable energy integration.

Yasmine Ihedrane born December 26, 1991 at FES, Morocco, she obtained her master's degree in Engineering of Industrial Automated Systems at the Faculty of Sciences Dhar el Mahrez FES- where he currently works, $\mathrm{PhD}$. graduate student in the same university and is a member laboratory LISTA. Her interests in machine control.

Badre Bossoufi was born in Fez city, Morocco, on May 21, 1985. He received the $\mathrm{PhD}$ degree in Electrical Engineering from University Sidi Mohammed Ben Abdellah, Faculty of Sciences, Morocco and $\mathrm{PhD}$ degree from University of Pitesti, Faculty of Electronics and Computer, Romanie and Montefiore Institute of electrical engineering, Luik, Belgium, in 2013. He was an Assistant Professor of Electrical Engineering, at the Higher School of technologie, Oujda Morocco. His research interests include static converters, electrical motor drives, power electronics, smart grid, renewable energy and artificial intelligent. 